\title{
Atypical Presentation of Idiopathic Intracranial Hypertension
}

\section{Aysel Milanlıoğlu', Ömer Faruk Odabaş²}

'Neurologist, Yüzüncü Yıl Üniversity, School of Medicine Department of Neurology, Van - Turkey ${ }^{2}$ Neurologist, Konya Ereğli State Hospital, Neurology Clinic, Konya - Turkey

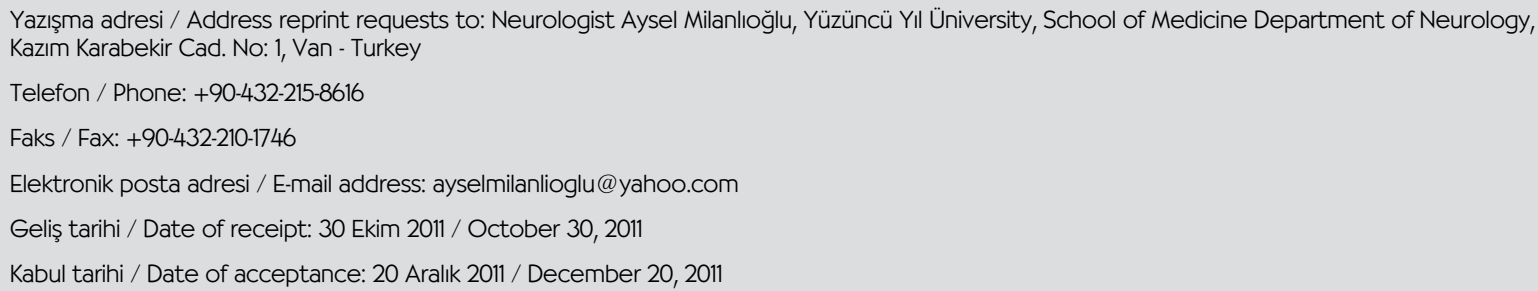

Dear Sir,

Idiopathic intracranial hypertension (IIH), also known as pseudotumor cerebri, is a disorder of elevated intracranial pressure in the absence of localizing neurological signs, intracranial mass lesions or cerebrospinal outflow obstruction (1).

The usual presentation is headache, pulsatile tinnitus, papilledema, visual disturbances, diplopia and vomiting $(2,3)$.

However, in some cases, involvement of cranial nerves can accompany and make the diagnosis difficult. We report a female case presented with headache, nausea, vomiting, diplopia, unilateral abducens nerve palsy with papilledema and diagnosed with IIH.

\section{CASE}

A 32-year-old woman was admitted to our outpatient clinic with a month history of severe, daily, throbbing bitemporal headache and persistent nausea, sometimes vomiting, and also diplopia for 4 days. The headache was very different from her previous ones and was the worst she had ever experienced. It worsened in the morning and exacerbated with the valsalva maneuver.

On neurological examination, she had an entire right lateral rectus immobility and funduscopy showed bilateral papilledema. Her past medical history was unremarkable and she had not been taking any drugs known to influence intracranial pressure. She was not obese.

Her biochemical profile, including renal and hepatic functions, urine analysis, thyroid hormones, and vitamin B12 level were all normal.

Brain magnetic resonance imaging (MRI) showed an incidental finding of left frontal arachnoid cyst with no evidence of edematous brain (Figure 1). MR anjiography and venography studies confirmed no intracranial lesion or thrombosis. Lumbar puncture from the lateral position showed an opening pressure of $38 \mathrm{~cm}$ of water with normal biochemical and cytological composition. All the secondary causes of IIH were ruled out (Table 1).

Based on the features described above, the diagnosis of IIH with unilateral abducens nerve palsy was made. The patient was treated with prednisone $(1 \mathrm{mg} / \mathrm{kg} / \mathrm{day})$ and acetazolamide (15 mg/kg/day). Her papilledema, diplopia and abducens nerve palsy were ameliorated

\section{Table 1: Causes of Intracranial Hypertension}

\section{a- Idiopathic}

b- Symptomatic

Dural venous sinus thrombosis

Exogenous substances or certain drugs

Withdrawal from corticosteroids

Systemic diseases

Endocrine disturbances

Disorders of cerebral venous drainage

Obesity 

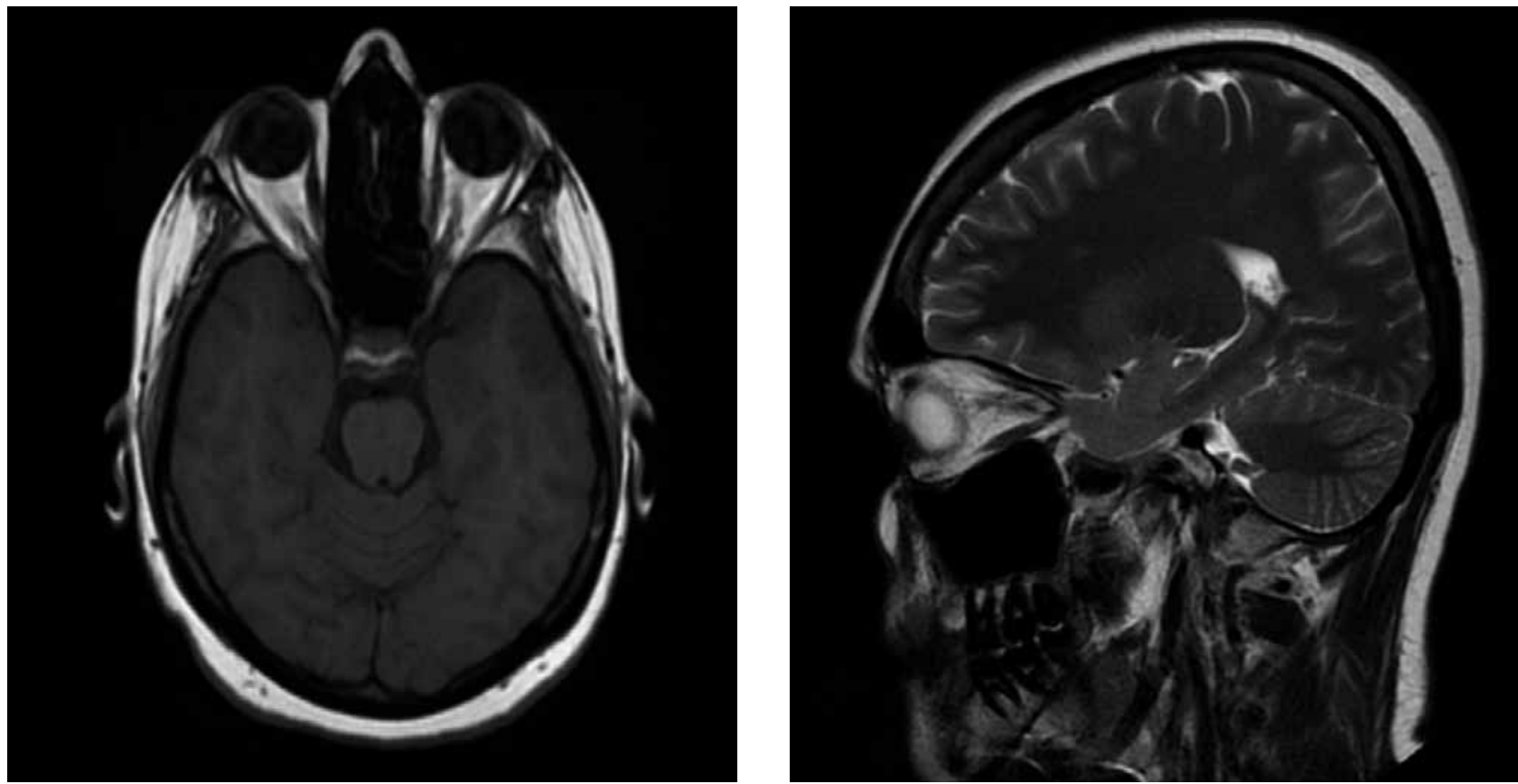

Figure 1: Brain magnetic resonance imaging (MRI) showed no marked abnormality

two weeks after the treatment with prednisone and acetazolamide. Prednisone was gradually reduced after the $15^{\text {th }}$ day of treatment and discontinued two weeks later. With the neuro-opthalmologic examination follow-up, acetazolamide was reduced and stopped after 3 months of treatment. She has been asymptomatic with no recurrence for 6 months.

Some patients who are nonrespondent to maximum medical therapy or who have progressive visual loss appear to benefit from surgical intervention. The two main surgical procedures are ventriculoperitoneal or lumboperitoneal shunting and optic nerve sheath fenestration (4).

\section{DISCUSSION}

In a case-control study, the most common symptoms reported by IIH patients were headache $(94 \%)$, transient visual obscuration (68\%), pulsatile tinnitus (58\%), photopsia (54\%), diplopia (38\%), vision loss $(30 \%)$ and retrobulbar pain on eye movements (22\%) (5).

Abducens nerve palsy is the most commonly described abnormality seen in association with IIH, although oculomotor, trochlear, trigeminal, facial, glossopharyngeal and hypoglossal nerve palsies have also been reported in isolated case reports (6).

Recent studies have shown that abducens nerve involvement can occur in $25-30 \%$ of the cases, usually in combination with the other symptoms and signs of IIH.

The pathophysiology of the cranial nerve palsies accompanying IHH is poorly understood. The probable mechanism of the sixth nerve involvement seems to be by stretching of the nerve across the petrous apex (7).

Previous diagnostic criteria for IIH required the condition of no localising neurological signs, but currently proposed criteria accept abducens nerve palsy, either unilateral or bilateral, as a false localising sign in IIH.

Finally, we present this patient due to the rare coexistence of IIH and sixth nerve palsy and because only limited cases of such patients have been presented in the literature, and we believe that neurologists should consider this coexistence while dealing with atypical presentation of IIH. 


\section{REFERENCES}

1. Sylaja PN, Moosa NV, Radhakrishnan K, Sarma PS, Kumar SP. Differential diagnosis of patients with intracranial sinus venous thrombosis related isolated intracranial hypertension from those with idiopathic intracranial hypertension. J Neurol Sci 2003; 215:9-12.

2. Wall M, George D. Idiopathic intracranial hypertension: a prospective study of 50 patients. Brain 1991; 114:155-180.

3. Milanlioglu A, Torlak PT. Intracranial hypertension and ciprofloxacin. Neurology India 2011; 59:302-303.

4. Bodkin PA, Hassan MF, Kane PJ, Brady N, Whittle IR. Surgical causes of benign intracranial hypertension. J R Soc Med 2008; 101:259-261.
5. Giuseffi V, Wall M, Siegel PZ, Rojas PB. Symptoms and disease associations in idiopathic intracranial hypertension (pseudotumor cerebri): a case-control study. Neurology 1991; 41:239-244.

6. Tzoufi M, Makis A, Grammeniatis V, Nakou I, Exarchakos G, Asproudis I, Zikou A, Argyropoulou M, Siamopoulou-Mavridou A. Idiopathic intracranial hypertension and facial palsy: case report and review of the literature. J Child Neurol 2010; 25:1529. 1534.

7. Bakshi SK, Oak JL, Chawla KP, Kulkarni SD, Apte N. Facial nerve involvement in pseudotumor cerebri. J Postgrad Med 1992; 38:144-145. 